\title{
Compact Modified Printed Monopole Antenna for Enhanced Gain Performance
}

\author{
Laila D \\ CREMA, Cochin University \\ of Science and Technology, \\ Cochin, Kerala
}

\author{
Sujith R \\ CREMA, Cochin University \\ of Science and Technology, \\ Cochin, Kerala
}

\author{
Nijas C M \\ CREMA, Cochin University \\ of Science and Technology, \\ Cochin, Kerala
}

\author{
Sarin V P \\ CREMA, Cochin University of Science and \\ Technology, \\ Cochin, Kerala
}

\author{
Mohanan $\mathrm{P}$ \\ CREMA, Cochin University of Science and \\ Technology, \\ Cochin, Kerala
}

\begin{abstract}
A novel Coplanar Waveguide (CPW) fed modified printed monopole antenna with enhanced gain is presented in this paper. The antenna has a maximum gain of $6.88 \mathrm{dBi}$ with a $2: 1$ VSWR band width of $45 \%$ from $1.99 \mathrm{GHz}$ to $3.03 \mathrm{GHz}$. High gain performance is achieved by folding the ground plane of a CPW fed printed monopole perpendicular to the plane of the monopole main arm. The antenna exhibits good radiation and impedance matching characteristics as that of a CPW fed ordinary printed monopole. The antenna has a dimension of $17 \times 42 \times 6.4 \mathrm{~mm}^{3}$ and highly suitable for slim mobile handsets.
\end{abstract}

\section{Keywords}

Coplanar Waveguide (CPW) fed monopole antenna, Enhanced gain.

\section{INTRODUCTION}

Monopole antennas have found widespread applications, especially in wireless communications, because of its simple structure, broad bandwidth and omni-directional radiation pattern, [1]. In recent years, there has been a move towards the CPW fed printed-monopole antenna in which the two ground plane and the monopole arm are printed on the same plane on a dielectric substrate [2]. However, the necessity of compactness has induced the research community to investigate folded main radiating elements $[3,4]$.The main disadvantage of such antennas is that it effects the radiation pattern and the impedance matching performance of the antenna adversely. So special feeding techniques and particular grounding systems have to be designed in order to obtain an acceptable compromise between compact dimensions and good radiating performance [5]. Moreover, the major drawback of the planar monopole antenna is their relative low gain. The gain performance can be enhanced by adding a superstrate of high dielectric constant on top of the antenna structure [6]. When antennas with relatively high gains are needed, the Yagi-Uda antenna is preferable. It is made as an array of parallel dipoles or monopoles, with reflector and the directors [7].The gain improvement with reduced bandwidth is obtained by using series of rectangular loop slots[8].Folded patch antenna in rectangular wave guide structure shape with complimentary split ring resonator is reported in [9] with $72 \%$ volume reduction. The proposed antenna is a modified version of the CPW fed monopole antenna and has a maximum gain of $6.88 \mathrm{dBi}$. The design is devoid of additional directors and reflectors required as in Yagi antenna and hence tremendous area reduction is achieved.

\section{ANTENNA GEOMETRY}

Antenna geometry is derived from a CPW fed planar monopole antenna by folding the ground plane perpendicular to the monopole main arm as shown in figure.1 (a) and figure.1 (b). The photograph of the proposed antenna geometry is shown in figure.1(c). The antenna parameters selected for the prototype are $\mathrm{L}_{1}=42 \mathrm{~mm}$ and $\mathrm{W}_{1}=3 \mathrm{~mm}$, with a folded ground plane dimension of $\mathrm{L}_{2}=17 \mathrm{~mm}, \mathrm{~W}_{2}=14 \mathrm{~mm}$ and $\mathrm{g}=1.7 \mathrm{~mm}$. The antenna is fabricated on a substrate of thickness $(\mathrm{h}) 1.6 \mathrm{~mm}$ and relative permittivity $\left(\varepsilon_{\mathrm{r}}\right)=4.4$ and occupies a volume of $14 \mathrm{X} 42 \mathrm{X} 6.4 \mathrm{~mm}^{3}$.To match with the present day slim handsets the overall width of the system is selected as $6.4 \mathrm{~mm}$.

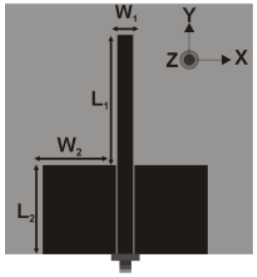

(a)
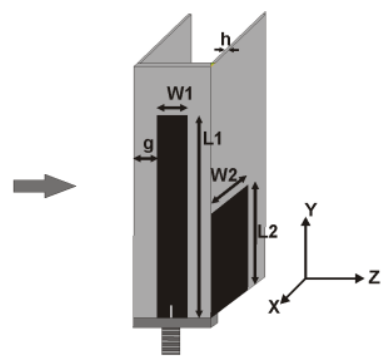

(b)

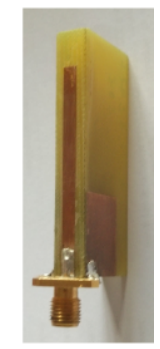

(c)
Figure.1. Geometry of the antenna (a) planar antenna (b) folded antenna (c) photograph of the antenna $\left(L_{1}=42 \mathrm{~mm}, W_{1}=3 \mathrm{~mm}\right.$, $\mathrm{L}_{2}=17 \mathrm{~mm}, \mathrm{~W}_{2}=14 \mathrm{~mm}, \mathrm{~g}=1.7 \mathrm{~mm}, \mathrm{~h}=1.6 \mathrm{~mm}, \varepsilon_{\mathrm{r}}=4.4$.)

\section{RESULTS AND DISCUSSION}

Measured (HP 8510C Vector Network Analyzer) and simulated (Ansoft HFSS) reflection characteristics of the $\mathrm{CPW}$ fed planar monopole and folded monopole are shown in figure.2. It is noted that both the antennas resonate at $2.3 \mathrm{GHz}$ and we can conclude that folding doesn't alter the resonating frequency of the monopole. The results show an excellent agreement between the measurement and simulation. The folded monopole shows a measured 2:1 VSWR bandwidth of $45 \%$ from $1.99 \mathrm{GHz}$ to $3.03 \mathrm{GHz}$. 


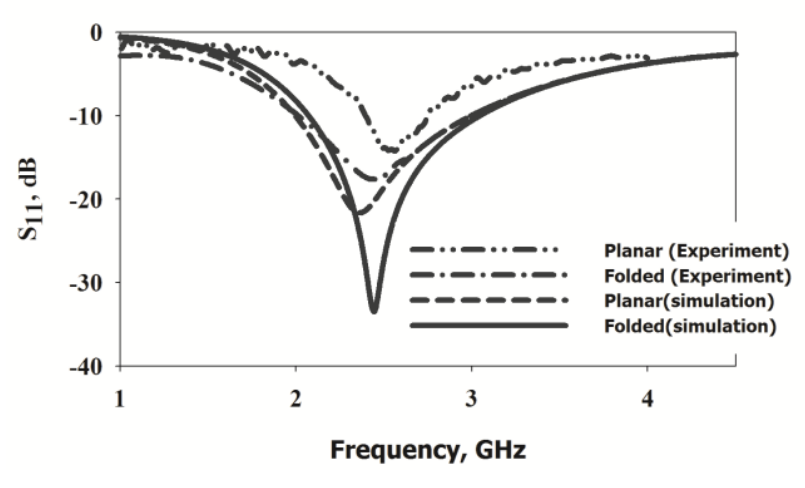

Figure.2. Reflection characteristics of planar and folded monopole antenna

Measured 2D radiation patterns in the $\mathrm{XZ}$ and $\mathrm{YZ}$ plane and the simulated $3 \mathrm{D}$ radiation pattern of the folded antenna are shown in figure. 3 and figure.4. respectively. It is noted that the folded antenna exhibits a non-directional pattern along the azimuth plane and is maintaining linear polarisation as that of ordinary monopole, throughout the band.
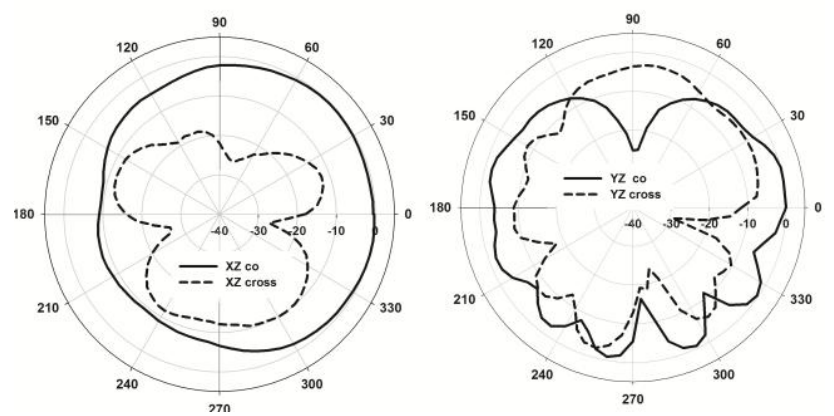

Figure.3. Measured radiation pattern of the folded antenna at resonant frequency (a) $\mathrm{XZ}$ plane (b) $\mathrm{YZ}$ plane

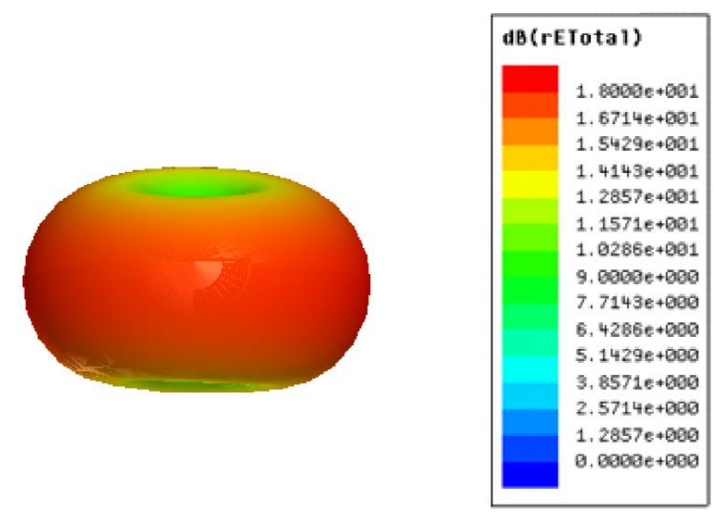

Figure 4 Simulated 3D radiation pattern of the folded antenna
Figure.5 shows the measured gain plot of the planar and folded antennas. It is interesting to note that the folded antenna has a maximum gain of $6.88 \mathrm{dBi}$, which is much greater than that of the conventional planar antenna (1.9dBi). A maximum gain enhancement of $4.077 \mathrm{dBi}$ is achieved at $2.54 \mathrm{GHz}$.

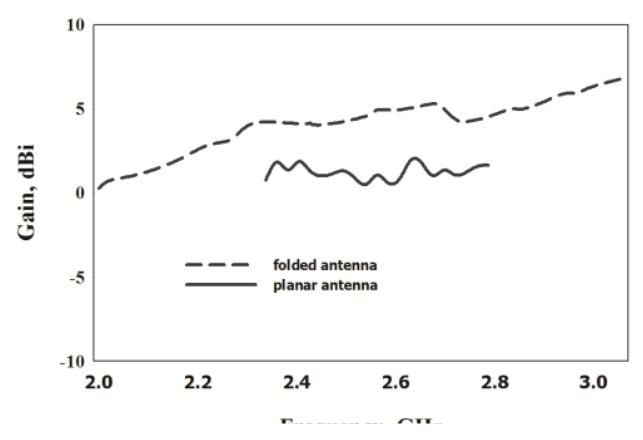

Figure.5 Measured gain of the antennas

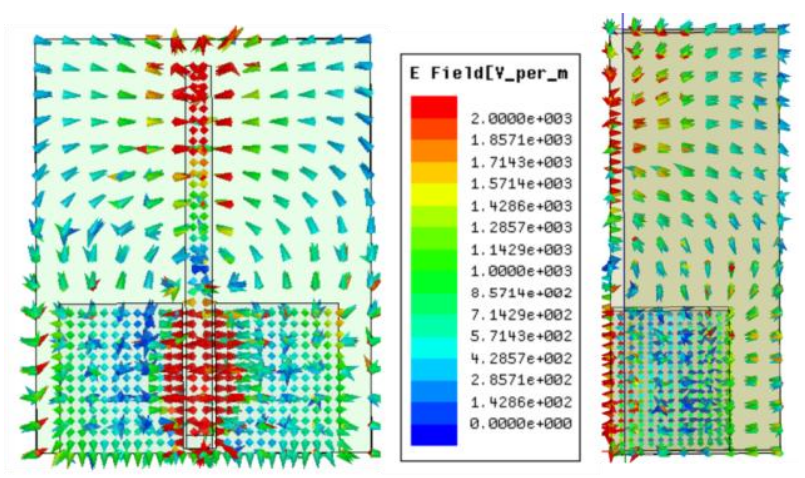

Figure.6 Simulated Electric field distribution at resonant frequencies of (a) planar monopole (b) folded monopole

The enhancement in gain can be best understood by comparing the fringing electric field patterns of the ordinary monopole and the folded monopole as shown in figure.6 (a) and (b). It is observed that the fringing electric field between the ground planes and the monopole arm are out of phase in the case of ordinary printed monopole antenna and it cancels the field at the far field giving reduced gain. But for the folded monopole, effectively adds the fringing fields at the bore sight giving an enhanced gain.

\section{CONCLUSION}

A novel compact folded monopole antenna with enhanced gain performance is presented .The antenna offers maximum gain of $6.88 \mathrm{dBi}$ with good radiation and matching characteristics. A gain enhancement of nearly $4 \mathrm{dBi}$ is observed at $2.54 \mathrm{GHz}$. The antenna is highly compact and hence it can be used with modern wireless handheld devices.

\section{ACKNOWLEDGEMENT}

The Authors would like to acknowledge Institute of Human resources and Development (IHRD), Govt of Kerala and Department of Science and Technology (DST), Govt. of India for financial assistance. 


\section{REFERENCES}

[1] P. Agrawall, G. Kumar, and K. Ray,'Wideband Planar Monopole Antennas', IEEE Trans on Antennas and Propagation.,vol-46,No 2, pp. 294-295, February 1998.

[2] Tzyh-Ghuang Ma, Chao-Hsiung Tseng, ,'An Ultrawideband Coplanar Waveguide-Fed Tapered Ring Slot Antenna., IEEE Trans on Antennas and Propagation, Vol. 54, No. 4, April 2006

[3] T. Tsukiji, Y. Kumon and M. Yamasaki,' Double-folded monopole antenna using parallel line or coaxial cable', IEE Proc.-Microw. Antennas Propag., Vol. 149, No. 1, pp.17-22,February 2002

[4] Z.N. Chen, M.Y.W. Chia and M.J. Ammann, 'Optimization and Comparison of Broadband Monopoles', IEE Proc.- Microw. Antennas Propag., Vol. 150, No. 6, pp.429-435, December 2003

[5] S.W. Su, K.L Wong and C.L. Tang, 'Ultra-wideband square planar monopole antenna for IEEE 802.16a operation in the 2-11 GHz Band', Microwave and
Optical Technology Letter, Vol. 42, No. 6, pp.463466,September 2004

[6] H.Y. Yang and N.G. Alexopoulos, 'Gain enhancement methods for printed circuit antennas through multiple Vol. 35,No.7, pp. 860-863, July 1987

[7] H. K. Kan, R. B. Waterhouse, A. M. Abbosh, and M. E. Bialkowski,' Simple Broadband Planar CPW-Fed Quasi-Yagi Antenna', IEEE Antennas and wireless popag letters, Vol. 6, pp 18-20, 2007

[8] Xing Chen, Kama Huang, and Xiao-Bang Xu "A novel planar slot array antenna with omni directional pattern", IEEE Trans on Antennas and Propagation, Vo. 59, No. 12, December 2011 ,pp4853-4857

[9] Xiaoyu Cheng*, Jun Shi, Cheolbok Kim, David Senior and Yong-Kyu Yoon "A Compact Self-packaged Patch Antenna with Non- Planar Complimentary Split Ring Resonator Loading" International symposium on antennas and propagation (APSURSI) 2011,pp 10361039. 